International Journal of Current Advanced Research

ISSN: O: 2319-6475, ISSN: P: 2319 - 6505, Impact Factor: SJIF: 5.995

Available Online at www.journalijcar.org

Volume 6; Issue 5; May 2017; Page No. 3595-3596

DOI: http://dx.doi.org/10.24327/ijcar.2017.3596.0324

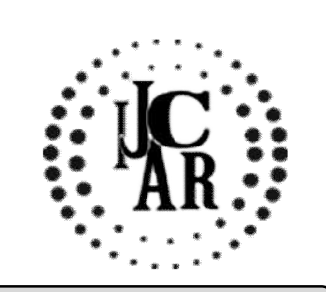

Research Article

\title{
ANTIBACTERIAL ACTIVITY OF PEPPERMINT OIL AGAINST ISOLATES OF ENTEROCOCCUS FAECALIS FROM DENTAL CARIES
}

\author{
Manoj Kumar KR ${ }^{1}$ and Gopinath P $^{2 *}$ \\ ${ }^{1}$ BDS 3rd year, Saveetha Dental College, Chennai \\ 2Department of Microbiology, Saveetha Dental College, Chennai
}

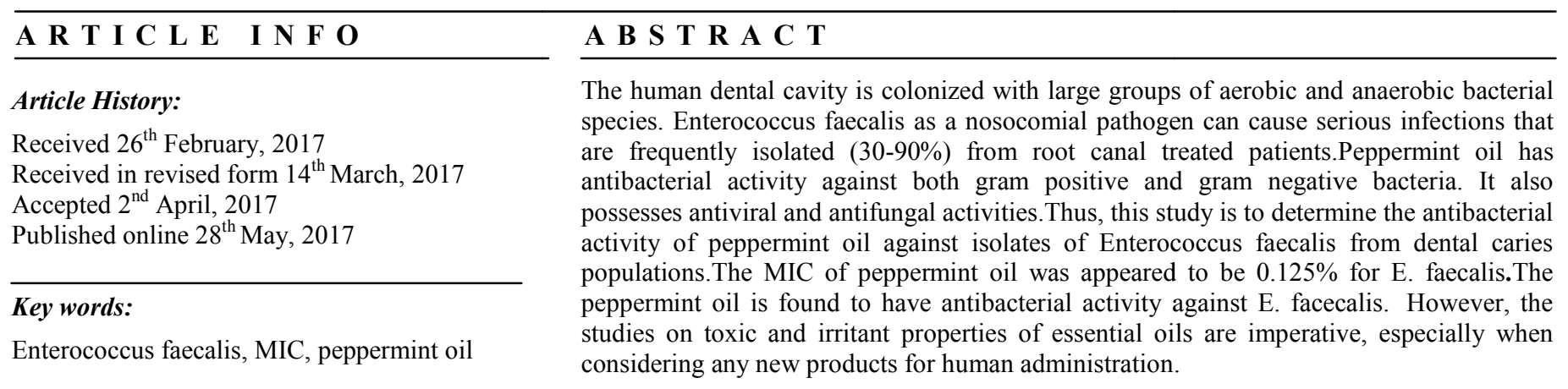

Copyright $\mathrm{C} 2017$ Manoj Kumar KR and Gopinath P. This is an open access article distributed under the Creative Commons Attribution License,

which permits unrestricted use, distribution, and reproduction in any medium, provided the original work is properly cited.

\section{INTRODUCTION}

The human dental cavity is colonized with large groups of aerobic and anaerobic bacterial species. Enterococcus faecalis as a nosocomial pathogen can cause serious infections that are frequently isolated (30-90\%) from root canal treated patients. [1] The high prevalence of this species in root canal treated patients evidenced by culturing methods, and molecular detection tools suggested that it may be the reason for most of the endodontic treatment failures. [2]

Peppermint oil has antibacterial activity against both gram positive and gram negative Bacteria. It also possesses antiviral and antifungal activities. The antiviral property shown to act against influenza, herpes viruses. [3]. Thus, this study is to determine the antibacterial activity of peppermint oil against isolates of Enterococcus faecalis from dental caries populations.

\section{MATERIALS AND METHODS}

\section{Clinical isolates}

A total of 20 different non-repetitive dental caries isolates of E. faecalis were collected included in this study. These isolates were identified by standard biochemical parameters as described by elsewhere. Isolates were preserved in semi-solid brain heart infusion medium and stored at $4^{\circ} \mathrm{C}$ until further use.

*Corresponding author: Gopinath $\mathbf{P}$

Department of Microbiology, Saveetha Dental College,

Chennai

\section{Antimicrobial susceptibility test}

Antibiotic susceptibility test was determined for these strains to routinely used antibiotics such as ampicillin $(10 \mu)$, vancomycin $(30 \mu)$, teicoplanin $(30 \mu)$, erythromycin $(15 \mu)$, ciprofloxacin $(5 \mu)$, amikacin $(200 \mu)$, gentamycin $(10 \mu)$, tetracycline $(30 \mu)$ and linezolid $(30 \mu)$ (Hi Media, Mumbai) by kirby-bauer disc diffusion method. [4]

\section{Detection of antibacterial activity of peppermint oil against E. faecalis}

Anti-bacterial activity of peppermint oil was tested against E. faecalis isolates by minimum inhibitory concentration method.Mueller Hinton broth was supplemented with $0.002 \%$ $(\mathrm{V} / \mathrm{V})$ tween 80 (HiMedia, Mumbai) toenhance the dispersion of the essential oil. Agar dilution method was performed to attain thedifferent concentrations of essential oils such as $0.03 \%, 0.06 \%, 0.125 \%, 0.25 \%, 0.5 \%, 1 \%$ and $2 \%$ in Mueller Hinton Agar (MHA).

Media containing various concentrations of essential oil were poured over the sterile petridishes and allowed to dry. Media without essential oil was served as control plate. Spot inoculation of $0.5 \mathrm{McFarland}$ standard turbidity adjusted isolates were made on the plates and incubated at $37^{\circ} \mathrm{C}$ for overnight. The lowest concentration of the essential oils that completely inhibited the growth of isolates was considered as MIC. [3] 


\section{RESULTS}

\section{Antibiotic susceptibility pattern}

We found increased percentage of isolates were shown to be resistant to all the antibiotics used in this study. For ampicillin, amikacin, erythromycin, gentamicin, our isolates were found to resistant between $80-90 \%$. Better sensitivity was observed in linezolid, teicoplanin and vancomycin antibiotics. The detailed results of antibiotic sensitivity patter of Enterococci was given in table 1.

Table 1 Results of antibiotic sensitivity patter of Enterococci

\begin{tabular}{cccc}
\hline Antibiotics & Sensitivity & Intermediate & Resistance \\
\hline Ampicillin & $1(5 \%)$ & $2(10 \%)$ & $17(85 \%)$ \\
Vancomycin & $15(75 \%)$ & $1(5 \%)$ & $4(20 \%)$ \\
Teicoplanin & $12(60 \%)$ & $3(15 \%)$ & $5(25 \%)$ \\
Erythromycin & $2(10 \%)$ & 0 & $18(90 \%)$ \\
Ciprofloxacin & $6(30 \%)$ & 0 & $14(70 \%)$ \\
Amikacin & $1(5 \%)$ & $1(5 \%)$ & $18(90 \%)$ \\
Gentamycin & $2(10 \%)$ & $2(10 \%)$ & $16(80 \%)$ \\
Tetracycline & $4(20 \%)$ & $4(20 \%)$ & $12(60 \%)$ \\
Linezolid & $18(90 \%)$ & $1(5 \%)$ & $1(5 \%)$ \\
\hline
\end{tabular}

Antibacterial activity of peppermint oil against isolates of Enterococcus faecalis

We have observed that, E. faecalis from dental carieswere inhibited from $0.125-1 \%$ of peppermint oil.

The MIC of peppermint oil was appeared to be $0.125 \%$ for E. faecalis.

\begin{tabular}{ccccccccc}
\hline $\begin{array}{c}\text { Dilutions of } \\
\text { Peppermint oil }\end{array}$ & $\mathbf{0 . 0 3} \%$ & $\mathbf{0 . 0 6} \%$ & $\mathbf{0 . 1 2 5} \%$ & $\mathbf{0 . 2 5} \%$ & $\mathbf{0 . 5} \%$ & $\mathbf{1 \%}$ & $\mathbf{2 \%}$ \\
\hline No. of organisms & 0 & 0 & $14(70 \%)$ & $2(10 \%)$ & $3(15 \%)$ & $1(5 \%)$ & 0 \\
\hline
\end{tabular}

\section{DISCUSSION}

Study conducted by Prakasam et al from Chennai in 2014 demonstrated that, Acinetobacter strains were inhibited from 0.06 to $0.25 \%, 0.25-1 \%$ and $0.125-1 \%$ for clove, peppermint and eucalyptus oils respectively. In clove oil, 14/50 (28\%) isolates were inhibited at $0.06 \%, 25 / 50(50 \%)$ at $0.125 \%$ and $11 / 50(22 \%)$ at $0.25 \%$ of clove oil. In peppermint oil, $34 / 50$ $(68 \%)$ isolates were inhibited at $0.25 \%, 12 / 50(24 \%)$ and $4 / 50$ $(8 \%)$ were at $0.5 \%$ and $1 \%$ concentrations of peppermint oil respectively. In eucalyptus oils, $10 / 50(20 \%)$ isolates were inhibited at $0.125 \%, 18 / 50(36 \%)$ at $0.25 \%, 16 / 50(32 \%)$ and $6 / 50(12 \%)$ were at $0.5 \%$ and $1 \%$ respectively. Thus, the MIC of clove oil was found to be $0.06 \%, 0.25 \%$ for peppermint oil and $0.125 \%$ for eucalyptus oil. [3]
In contrast, in our study, we used peppermint oil against E. faecalis isolates. $70 \%$ of isolates were inhibited at $0.125 \%$, $10 \%$ were at $0.25 \%, 15 \%$ were at $0.5 \%$ and $5 \%$ were at $1 \%$ of essential oil. Thus, the MIC of peppermint oil against E. faecalis was found to be $0.125 \%$.

\section{CONCLUSION}

The peppermint oil is found to have antibacterial activity against E. facecalis. However, the studies on toxic and irritant properties of essential oils are imperative, especially when considering any new products for human administration. This can be used as alternative and complementary antibacterial agents for controlling dental caries.

\section{References}

1. Bhalla A, Pultz NJ, Gries DM, Ray AJ, Eckstein EC, Aron DC, et al. 2004. Acquisition of nosocomial pathogens on hands after contact with environmental surfaces near hospitalized patients. Infect Control Hosp Epidemiol. 25(2):164-7.

2. Kayaoglu G, Ørstavik D. 2004. Virulence factors of Enterococcus faecalis: Relationship to endodontic disease. Crit Rev Oral Biol Med. 15(5):308-20.

3. Gopinath Prakasam, Manju Bhashini, Lakshmipriya, Srivani Ramesh S. 2014. In-vitro antibacterial activity of some essential oils against clinical isolates of Acinetobacter baumannii. Indian $J$ Med Microbiol. 32:90-91.

4. Clinical Laboratory Standards Institution: Performance standards for antimicrobial susceptibility testing. In NCCLS approved standard M2-A8. Wayne, PA USA: CLSI, 2004.

\section{How to cite this article:}

Hemani K and Kannan Rajendran (2017) ' Antibacterial Activity Of Peppermint Oil Against Isolates Of Enterococcus Faecalis From Dental Caries', International Journal of Current Advanced Research, 06(05), pp. 3595-3596. DOI: http://dx.doi.org/10.24327/ijcar.2017.3596.0324 